\title{
Impact of Algal Bloom on Mangrove and Coral Reef Ecosystem in the Marine National Park, Gulf of Kachchh, Gujarat, India
}

\author{
D. Adhavan ${ }^{1 *}$, N. Marimuthu' ${ }^{2}$, S. Tikadar ${ }^{3}$, K. Sivakumar ${ }^{1}$ \\ ${ }^{1}$ Wildlife institute of India, Chandrabani, Dehradun, India \\ ${ }^{2}$ Gujarat Ecology Commission, Gandhinagar, Gujarat, India \\ ${ }^{3}$ Office of CCF, MNP, Forest Campus, "Van Sankul", Jamnagar, Gujarat, India
}

*Corresponding Author: Adhavan, D. Wildlife institute of India Post Box No.18, Chandrabani, Dehradun -248001, India. Tel: +9445990266; E-mail: adhavmarine@gmail.com

Citation: Adhavan, D., et al. Impact of Algal Bloom on Mangrove and Coral Reef Ecosystem in the Marine National Park, Gulf of Kachchh, Gujarat, India. (2015) J Marine Biol Aquacult 1(2): 31-32.

\section{Introduction}

Algal blooms occur as a natural phenomena when environmental conditions promote the rapid growth of algae, which is faced by almost all coastal countries ${ }^{[1,2]}$. A severity of such algal blooms depends upon the nutrient enrichment level especially phosphorous and nitrogen contents in the ecosystem. Anthropogenic activities, natural sources, hydrographic changes and sometime climate change impacts are responsible to stimulate the growth of algae that causes intensive effect on the coastal ecosystems ${ }^{[3-6]}$. The primary source attributed to the triggering and spread of blooms is increasing the pollution. However, pollution is not always a noticeable factor that cannot be ignored.

Gulf of Kachchh Marine National Park (MNP) is one of the marine biodiversity rich habitats that include 42 islands. It is also known as non-divers' paradise where variety of marine organisms can be witnessed during low tide ${ }^{[7,8]}$. This Marine Protected Area is surrounded by various industries including petrochemicals, fertilizer, ship building, thermal power, salt works and several other small scale industries that drain their effluents into the sea ${ }^{[9,10]}$. In addition, the southwest monsoon downpours the region and washes the nutrients along with other pollutant from land to sea. It stimulates the nitrification in the Gulf of Kachchh waters and further results in algal bloom every year from October to February.

During our regular monthly survey for biodiversity assessment under the Integrated Coastal Zone Management Project (ICZMP) between the years 2013 and 2015, we could observe algal enrichment on intertidal reef environment of Pirotan Island, Narara and Poshitra reef and also in the mangrove ecosystem at Narara coastal area which is dominated by Avicennia marina followed by sparing distribution of Ceriops tagal and Rhizophora mucronata (Table 1). Every season, algal species Ulva lactuca (Family, chlorophyceae) was found to be dominant during algal blooms, followed by Sargassum cinereum, $S$. tenerrimum (Family, pheophyceae). Other species such as Ulva prolifera, Caulerpa racemosa, C. taxifolia, Ectocarpus siliculosus, Padina tetrastromatica were also found but their abundances were comparatively less.

Table 1: GPS coordinates of impacted sites.

\begin{tabular}{|l|l|l|l|}
\hline $\begin{array}{l}\text { S1. } \\
\text { No }\end{array}$ & Name of the Site & GPS coordinates & $\begin{array}{l}\text { Occurrences of } \\
\text { algal bloom }\end{array}$ \\
\hline 1. & Narara Reef & $\begin{array}{l}22^{\circ} 2849.34 ” \mathrm{~N}, 69^{\circ} 42^{\prime} \\
44.17^{\prime} \mathrm{E}\end{array}$ & Oct-Feb \\
\hline 2. & $\begin{array}{l}\text { Narara mangrove } \\
\text { ecosystem }\end{array}$ & $\begin{array}{l}22^{\circ} 28^{\prime} 10.59^{\prime}, \mathrm{N}, 69^{\circ} \\
43^{\prime} 23.93^{\prime} \mathrm{E}\end{array}$ & Nov-Feb \\
\hline 3. & Pirotan Island & $\begin{array}{l}22^{\circ} 35^{\prime} 33.41^{\prime \prime} \mathrm{N}, 69^{\circ} \\
57^{\prime} 13.26^{\prime} \mathrm{E}\end{array}$ & Nov-Jan \\
\hline 4. & Poshitra reef & $\begin{array}{l}22^{\circ} 24^{\prime} 58.57^{\prime} \mathrm{N}, 69^{\circ} \\
11^{\prime} 37.87^{\prime} \mathrm{E}\end{array}$ & Nov-Feb \\
\hline
\end{tabular}

The bloom drastically affected the mangrove ecosystem (Figure 1) at Narara coastal area and settled over the dead portion of the massive form of hard corals at Pirotan Islands (Figure 1). It was also observed that algal mat covered the pneumatophores (breathing roots) and leaves of mangroves which hampers breathing and photosynthetic processes. Whereas in inter-tidal ecosystem, they formed a thick coat (Figure 1) over the sedentary organisms including corals, sponges, anemones, etc., and restricted the sunlight which might have affected the 
primary productivities of their symbionts. The seaweed bloom indicates the decrease of fish grazers in the coast. Few fish and other animals including mullet, mudskippers, crabs, etc., were found dead during this algal bloom in the mangrove areas. Further, fishes were found avoiding the bloom areas that affects the livelihoods of local communities who rely on traditional fisheries in the region.

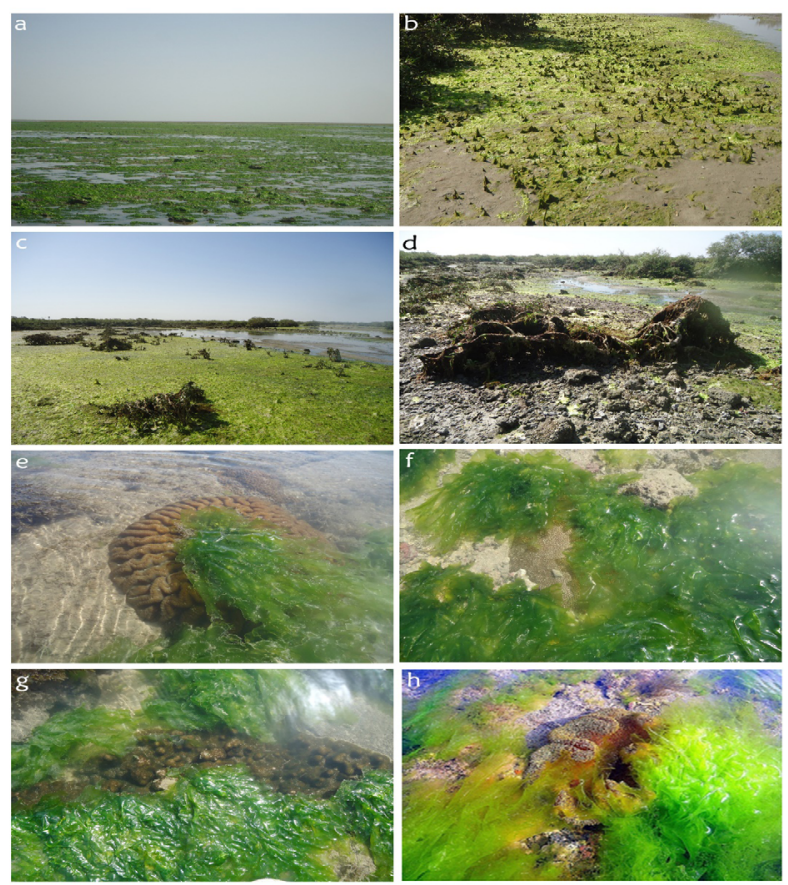

Figure 1: Impact of algal bloom on intertidal (a), Mangrove (b-d) and Coral reef (e, Symphyllia sp., f, Siderastrea sp., g, Porites sp., h, Anemone, Stichodactyla sp.) ecosystem of Marine National Park, Gulf of Kachchh.

The seaweed bloom could be a biological indicator for pollution and decrease of fish catch in the coast. It would be a poor effect on the ecosystems if the situation continues with a decrease in fish population which would also impact the sedentary organisms' recruitment process. However, this seaweed can be used for manure production, pharmaceuticals, cosmetics industries, therefore, manual harvesting of seaweed outside the Marine National Park without affecting the ecosystem is recommended as an alternate livelihood for the fisher folk along the coast of the Gulf.

\section{Acknowledgements}

The authors are gratefully acknowledged the State Project Management Unit, Integrated Coastal Zone Management Project, Gujarat Ecology Commission, Gandhinagar for the financial support. Thanks are due to continuous support rendering from DCF and ACF, and frontline staff of Marine National Park, Jamnagar, India.

Conflict of Interest: There are no Conflicts of interest.

\section{References}

1. Anderson, D.M., Burkholder, J.M., Cochlan, W.P., et al. Harmful algal blooms and eutrophication: Examining linkages from selected coastal regions of the United States. (2008) Harmful Algae 8(1): 39-53. 2. Simon, A., Shanmugam, P. An Algorithm for Classification of Algal Blooms Using MODIS-Aqua Data in Oceanic Waters around India. (2012) Advances in Remote Sensing 1(2): 35-51.

3. Anderson, D.M., Glibert, P.M., Burkholder, J.M. Harmful Algal Blooms and Eutrophication: Nutrients Sources, Composition, and Consequences. (2002) Estuaries 25(4): 704-726.

4. Sellner, K.G., Doucette, G.J., Kirkpatrick, G.J. Harmful Algal Blooms: Causes, Impacts and Detection. (2003) Journal of Industrial Microbiology and Biotechnology 30 (7): 383-406 .

5. Bhat, S.R., Prabhu Matondkar, S.G. Algal blooms in the seas around India - Networking for research and outreach. (2004) Curr Sci 87(8): 1079-1083.

6. Xingyu, S., Liangmin, H., Jianlin, Z., et al. Harmful algal blooms (HABs) in Daya Bay, China: an in Situ Study of Primary Production and Environmental Impacts. (2009) Mar Pollut Bull 58(9): 1310-1318 . 7. Nair, V. R. Status of Flora and Fauna of Gulf of Kachchh. (2013) 87: 157.

8. Adhavan, D., Kamboj, R.D., Marimuthu, N., et al. Seasonal variation and climate change influence coral bleaching in Pirotan Island, Gulf of Kachchh Marine National Park, Gujarat. (2014) Curr Sci 107(11): 1780-1781.

9. Geographical Information System of Gulf of Kachchh (2002) Integrated Coastal and Marine Area Management (ICMAM) 1-53.

10. Adhavan, D., Kamboj, R.D., Chavda, D.V., et al. Status of Intertidal Biodiversity of Narara Reef Marine National Park, Gulf of Kachchh, Gujarat. (2014) J Mar Biol Oceanogr 3(3). 